\section{Laparoscopic radiofrequency ablation versus percutaneous radiofrequency ablation for subphrenic hepatocellular carcinoma}

\author{
Min Hwan Kwak', Min Woo Lee ${ }^{1,2}$, Seong Eun Ko ${ }^{1}$, Hyunchul Rhim ${ }^{1,2}$, Tae Wook Kang ${ }^{1,2}$, \\ Kyoung Doo Song ${ }^{1,2}$, Jong Man Kim ${ }^{3}$, Gyu-Seong $\mathrm{Choi}^{3}$ \\ ${ }^{1}$ Department of Radiology and Center for Imaging Science, Samsung Medical Center, \\ Sungkyunkwan University School of Medicine, Seoul; ${ }^{2}$ Department of Health Sciences and \\ Technology, SAIHST, Sungkyunkwan University, Seoul; ${ }^{3}$ Department of Surgery, Samsung \\ Medical Center, Sungkyunkwan University School of Medicine, Seoul, Korea
}

Purpose: Radiofrequency ablation is a curative treatment option for very early-stage or earlystage hepatocellular carcinoma (HCC). However, percutaneous radiofrequency ablation (PRFA) for subphrenic tumors is technically challenging. Laparoscopic radiofrequency ablation (LRFA) has been used to overcome this disadvantage. This study compared the treatment outcomes between LRFA and PRFA for subphrenic HCC.

Methods: This retrospective study screened patients who underwent PRFA or LRFA for subphrenic HCC between 2013 and 2018. Therapeutic outcomes, including local tumor progression (LTP), intrahepatic distant recurrence (IDR), extrahepatic metastasis (EM), disease-free survival (DFS), and overall survival (OS), were compared between the two groups.

Results: Thirty patients in the PRFA group and 23 patients in the LRFA group were included. LTP was observed in six patients in the PRFA group (20\%), but in no patients in the LRFA group. The cumulative LTP rates at 1, 3, and 5 years were $3.7 \%, 23.4 \%$, and $23.4 \%$, respectively, in the PRFA group and $0.0 \%$ in the LRFA group $(P=0.015)$. The IDR, EM, and DFS rates were not significantly different between the two groups $(\mathrm{P}=0.304, \mathrm{P}=0.175$, and $\mathrm{P}=0.075$, respectively). The OS rates at 1,3 , and 5 years were $96.6 \%, 85.7 \%$, and $71.6 \%$, respectively, in the PRFA group and $100 \%, 95.7 \%$, and $95.7 \%$, respectively, in the LRFA group ( $\mathrm{P}=0.049$ ).

Conclusion: LRFA demonstrated better therapeutic outcomes than did PRFA for subphrenic tumors in terms of LTP and OS. Therefore, LRFA can be considered as the first-line treatment option for subphrenic HCC.

Keywords: Radiofrequency ablation; Laparoscopy; Hepatocellular carcinoma; Diaphragm; Local tumor progression

Key points: Laparoscopic radiofrequency ablation can be considered as treatment option for subphrenic hepatocellular carcinoma.

e-ultrasonography.org

Ultrasonography 41(3), July 2022

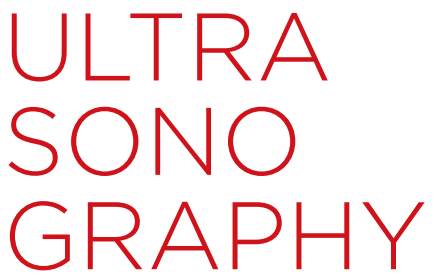

ORIGINAL ARTICLE

https://doi.org/10.14366/usg.21241 pISSN: 2288-5919 • elSSN: 2288-5943 Ultrasonography 2022;41:543-552

Received: November 17, 2021

Revised: January 20, 2022

Accepted: February 9, 2022

Correspondence to:

Min Woo Lee, MD, PhD, Department of Radiology and Center for Imaging Science, Samsung Medical Center, Sungkyunkwan University School of Medicine, 81 Irwon-ro, Gangnam-gu, Seoul 06351, Korea

Tel. +82-2-3410-2518

Fax. +82-2-3410-2559

E-mail: leeminwoo0@gmail.com

This is an Open Access article distributed under the terms of the Creative Commons Attribution NonCommercial License (http://creativecommons.org/ licenses/by-nc/4.0/) which permits unrestricted noncommercial use, distribution, and reproduction in any medium, provided the original work is properly cited.

Copyright (C) 2022 Korean Society of Ultrasound in Medicine (KSUM)

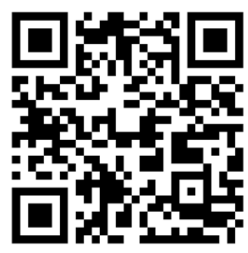

How to cite this article:

Kwak MH, Lee MW, Ko SE, Rhim H, Kang TW Song KD, et al. Laparoscopic radiofrequency ablation versus percutaneous radiofrequency ablation for subphrenic hepatocellular carcinoma. Ultrasonography. 2022 Jul:41(3):543-552. 


\section{Introduction}

Radiofrequency ablation (RFA) is a curative treatment option for hepatocellular carcinoma (HCC). It is recommended for patients with very early-stage or early-stage HCC without optimal indications for surgery or transplantation [1]. The treatment outcomes after RFA are affected by tumor location. For example, although debate continues, subcapsular tumors have been considered problematic for percutaneous RFA (PRFA) [2]. However, some studies have shown that the results of RFA for subcapsular HCC are comparable to those for non-subcapsular HCC [3-7]. Conversely, subphrenic tumors, a subtype of subcapsular HCC, are still considered challenging to ablate via PRFA because of technical difficulties. Although some supportive skills, such as artificial ascites or pleural effusion, reduce the local tumor progression (LTP) rate after PRFA for subphrenic HCC [8-10], many studies have reported that subphrenic tumor location is a significant risk factor for LTP after PRFA $[3,11,12]$. Surprisingly, a previous study has reported that peritoneal seeding was found in up to approximately $10 \%$ of patients after ultrasound (US)-guided PRFA for subphrenic HCC [12].

Laparoscopic RFA (LRFA) has been attempted to overcome the technical difficulty of PRFA for subphrenic HCC, as it has various advantages over PRFA in terms of technical merits and survival outcomes [13]. A recent study showed that LRFA for treating subphrenic HCC had high technical efficacy and a very low LTP rate [14]. Therefore, it is postulated that LRFA would show better treatment outcomes than would PRFA for subphrenic HCC. However, to the authors' knowledge, no study has directly compared the therapeutic outcomes between LRFA and PRFA for subphrenic HCC.

Therefore, this study aimed to compare the treatment outcomes of LRFA with those of PRFA for subphrenic HCC.

\section{Materials and Methods}

\section{Compliance with Ethical Standards}

This retrospective study was approved by the Institutional Review Board of Samsung Medical Center (2021-06-086), and the requirement for informed consent was waived.

\section{Patients}

This study used a longitudinal hospital registry from a single tertiary referral hospital. Patients who underwent either PRFA or LRFA as primary HCC treatment between January 2013 and December 2018 were included. In total, 1,816 patients were treated with PRFA. Among them, 1,565 were excluded for the following reasons: HCC treatment history $(n=1,164)$, loss to follow-up after 1 month $(n=35)$, other concurrent malignancy $(n=160)$, multiple HCCs $(n=32)$, HCC size of $>3 \mathrm{~cm}(n=22)$, and tumor size of $<1 \mathrm{~cm}(n=152)$. Tumor size was measured in the sequences that showed the best conspicuity of the tumor in dynamic enhanced liver magnetic resonance imaging (MRI). If the tumor had low signal intensity on the hepatobiliary phase, that sequence was preferred, and the longest diameter of the tumor was measured on either axial or coronal images. Two radiologists reviewed the computed tomography (CT) and MRI scans obtained before RFA and reached a consensus on the tumor location (subphrenic or non-subphrenic). Finally, 221 patients were further excluded because the HCC had a non-subphrenic location. Subphrenic tumors were defined as those abutting the diaphragm. Tumor size was defined based on the longest diameter on CT or MRI. Finally, 30 patients treated with PRFA for subphrenic HCC were included.

LRFA was performed in 124 patients. Among them, 84 were excluded for the following reasons: HCC treatment history $(n=74)$, other concurrent malignancy $(n=2)$, multiple HCCs $(n=6), H C C$ size of $>3 \mathrm{~cm}(n=1)$, and advanced HCC with bile duct invasion $(n=1)$. The pretreatment images were also reviewed, and 17 patients were excluded due to tumors with a non-subphrenic location. Finally, 23 patients treated with LRFA for subphrenic HCC were included. Fig. 1 shows the flow diagram of patient selection. The HCC diagnosis was based on current clinical guidelines [15].

\section{Percutaneous RFA}

Planning US was performed by interventional radiologists to assess whether PRFA was feasible using fusion imaging (Volume navigation, LOGIQ E9, GE Healthcare, Chicago, IL, USA) of B-mode US and pretreatment CT/MRI, obtained within 1 month prior to the procedure [16]. Fusion imaging was routinely used for treatment planning regardless of lesion conspicuity. When PRFA was considered feasible, it was attempted by the same radiologists, who had more than 3 years of experience in RFA for hepatic tumors.

Radiofrequency electrodes were inserted under fusion imaging guidance; direct tumor puncture was avoided when the tumor was located in the anterior liver dome to prevent peritoneal seeding. Based on the tumor size and location, the choice was made to use an active tip length-adjustable internally cooled tip (Proteus RF Electrode, STARmed, Goyang, Korea), an internally cooled wet tip, a kind of perfusion electrode with various active tip lengths (Jet-tip, RF Medical, Seoul, Korea), or clustered separable electrodes with an internally cooled tip with different active tip length (Octopus Electrode, STARmed). To achieve a sufficient ablative margin, peripheral tumor-puncturing or no-touch RFA was preferred when using multiple electrodes or overlapping ablation when using a single electrode. The radiologist ensured that the index tumor was completely covered in the RFA zone based on US findings. The tract 
1,940 Patients who underwent either percutaneous or laparoscopic RFA for HCC from January 2013 to December 2018

,816 Patients who underwent percutaneous RFA

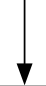

1,565 Patients excluded

- 1,164 Previous history of HCC

- 160 Concurrent other malignancy

- 32 Multiple HCCs

- 22 HCC larger than $3 \mathrm{~cm}$

- $152 \mathrm{HCC}$ smaller than $1 \mathrm{~cm}$

- 35 No follow-up after 1 month

221 Patients were excluded for non-subphrenic location of HCC

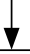

30 Percutaneous RFA group with a single treatment-naive subphrenic $\mathrm{HCC} \leq 3 \mathrm{~cm}, \geq 1 \mathrm{~cm}$
124 Patients who underwent laparoscopic RFA

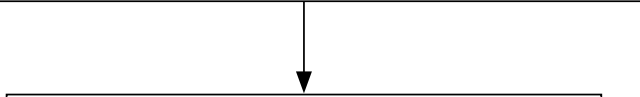

84 Patients excluded

- 74 Previous history of HCC

- 2 Concurrent other malignancy

- 6 Multiple HCCs

- $1 \mathrm{HCC}$ larger than $3 \mathrm{~cm}$

- 1 Advanced HCC with bile duct invasion

17 Patients were excluded for non-subphrenic location of HCC

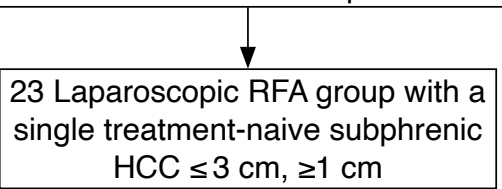

Fig. 1. Flow diagram of patient selection for the study. HCC, hepatocellular carcinoma; RFA, radiofrequency ablation.

was cauterized during electrode removal.

\section{Laparoscopic RFA}

LRFA was considered after planning US when the subphrenic HCC location appeared technically challenging for PRFA. When both PRFA and LRFA were feasible, the treatment method was determined by the radiologist. LRFA was performed by one of three radiologists while the patient was under general anesthesia. The surgeons introduced three or four trocars through the subcostal and subumbilical areas. The patients' positions were manipulated to insert the radiofrequency electrode in the appropriate direction. A single electrode (Proteus RF Electrode, STARmed) or clustered separable electrodes (Octopus Electrode, STARmed) were used.

When the subphrenic tumors were broadly attached to the anterior liver capsule, they were well visualized on laparoscopy. The radiofrequency electrodes were inserted in parallel under laparoscopic guidance [14]. Whenever needed, overlapping ablations were performed for complete ablation with a sufficient ablative margin. Direct tumor puncture was avoided (video clip). Laparoscopic US (Aloka Inc., Tokyo, Japan) was also used for tumors focally attached to the liver capsule; thus, the tumors were not visualized on laparoscopy. The liver capsule was cauterized on top of the index tumor based on laparoscopic US findings for tumors not visible on laparoscopy, which facilitated accurate electrode placement. The electrode's position in relation to the index tumor was assessed using laparoscopic US. The RFA zone was monitored to ensure that it was large enough to cover the entire tumor using laparoscopy and US. The tract was ablated during electrode removal.

\section{Treatment Response and Complications}

Treatment response and complications were evaluated using contrast-enhanced CT on the day of the RFA. Treatment was considered technically successful if the RFA zone completely covered the index tumor on CT images [17]. A second RFA session was attempted within 24 hours after the first RFA session if technical success was not achieved. Technical efficacy was assessed on a 1-month follow-up CT or MRI scan. Major complications were defined as events that led to substantial morbidity and disability that increased the level of care, resulted in hospital admission, or substantially lengthened the hospital stay. All other complications were considered minor [17].

\section{Follow-up}

Follow-up contrast-enhanced CT/MRI was performed 1 month after initial treatment, every 3-4 months during the first 2 years, and every 4-6 months thereafter. Chest radiography, serum alphafetoprotein level measurements, and liver function tests were also performed. LTP was defined as the appearance of tumor foci at the edge of the ablation zone [17]. If recurrence, including LTP, intrahepatic distant recurrence (IDR), and extrahepatic metastasis (EM), occurred during follow-up, the multidisciplinary team decided on a suitable second-line treatment. 


\section{Comparison of Therapeutic Outcomes}

The length of the ablation zone was measured in 3-dimensions on immediate post-RFA CT. The maximum (Dmax) and minimum (Dmin) diameters of the ablation zone were measured from axial $\mathrm{CT}$ images and the longest vertical diameter (Dv) from coronal or sagittal images. The ablation volume was calculated using the formula for an ellipsoid lesion: ablation volume $=\pi(D \max \times$ Dmin $\times$ Dv $) / 6$ [18]. The ratios of the longest diameter and volume of ablation zone to those of the tumors were compared between the PRFA and LRFA groups.

Therapeutic outcomes, including LTP, IDR, EM, disease-free survival (DFS), and overall survival (OS), were compared between the two groups. DFS was defined as the time from the day of ablation to recurrence or death. OS was defined as the time from the initial treatment to death or the last follow-up date before April 30, 2021.

\section{Statistical Analyses}

Demographic and clinical characteristics between the groups were compared using the $t$ test, Wilcoxon rank-sum test, chi-square test, or Fisher exact test, as appropriate. Kaplan-Meier survival curves and the log-rank test were used to compare the cumulative LTP, IDR, EM, DFS, and OS rates. Statistical analyses were performed using SAS version 9.4 (SAS Institute, Cary, NC, USA). Statistical significance was set at $\mathrm{P}<0.05$.

\section{Results}

\section{Baseline Characteristics}

The baseline characteristics of the patients, which are summarized in Table 1, were not significantly different between the PRFA and LRFA groups. Liver function, assessed using the Child-Pugh class or albumin-bilirubin grade, was not significantly different between the two groups. The serum levels of alpha-fetoprotein and protein induced by vitamin $\mathrm{K}$ absence-II were also not significantly different. More than $70 \%$ of the patients had hepatitis B virus-related liver disease, and the cause of liver disease was not significantly different between the two groups. The tumor size and location (Couinaud segment) were also not significantly different. The characteristics of the ablation technique are summarized in Table 2. They were not significantly different between the PRFA and LRFA groups.

\section{Technical Success and Efficacy of RFA}

In the PRFA group, a residual unablated tumor was noted in one patient $(3.3 \%)$ on the immediate post-RFA CT images. The second RFA session was performed on the same day, which led to successful local tumor control. Technical efficacy was achieved in 30 patients (100\%). Four of the 23 tumors in the LRFA group were indistinguishable on laparoscopy. These tumors were localized using
Table 1. Demographic and clinical characteristics of the study patients

\begin{tabular}{|c|c|c|c|}
\hline Variable & $\begin{array}{l}\text { Percutaneous RFA } \\
(n=30)\end{array}$ & $\begin{array}{l}\text { Laparoscopic RFA } \\
\qquad(n=23)\end{array}$ & P-value \\
\hline Age (year) & $56.7 \pm 11.3$ & $61.2 \pm 8.0$ & 0.106 \\
\hline Male sex & $21(70.0)$ & $18(78.3)$ & 0.499 \\
\hline Cause of liver disease & & & 0.430 \\
\hline HBV infection & $23(76.7)$ & $17(73.9)$ & \\
\hline HCV infection & $4(13.3)$ & $1(4.4)$ & \\
\hline Others & $3(10.0)$ & $5(21.7)$ & \\
\hline AFP level & $46.9 \pm 70.6$ & $13.6 \pm 27.2$ & 0.054 \\
\hline $\log ($ AFP) & $2.8 \pm 1.5$ & $2.0 \pm 0.9$ & 0.054 \\
\hline PIVKA-II level & $25.5(20.0-36.5)$ & $25.5(18.0-42.0)$ & 0.653 \\
\hline Platelet count $\left(\times 10^{9} / \mathrm{L}\right)$ & $118(77-177)$ & $118(77-166)$ & 0.900 \\
\hline $\begin{array}{l}\text { Total bilirubin level } \\
(\mathrm{mg} / \mathrm{dL})\end{array}$ & $0.6(0.4-1.4)$ & $0.7(0.4-1.2)$ & 0.836 \\
\hline Albumin level (g/dL) & $4.3(3.9-4.6)$ & $4.4(4.1-4.6)$ & 0.516 \\
\hline \multicolumn{4}{|l|}{ Child-Pugh class } \\
\hline$A / B$ & $28(93.3) / 2(6.7)$ & $22(95.7) / 1(4.4)$ & $>0.999$ \\
\hline \multicolumn{4}{|l|}{ ALBI grade } \\
\hline $1 / 2 / 3$ & $\begin{array}{c}22(73.3) / 7(23.3) / \\
1(3.3)\end{array}$ & $\begin{array}{c}19(82.6) / 4(17.4) / \\
0(0)\end{array}$ & 0.850 \\
\hline Prothrombin time (INR) & $1.1(1.0-1.2)$ & $1.1(1.0-1.2)$ & 0.189 \\
\hline Creatinine level (mg/dL) & $0.9(0.8-1.1)$ & $0.9(0.8-1.0)$ & 0.914 \\
\hline Tumor size (cm) & $1.9(1.6-2.1)$ & $1.6(1.3-1.9)$ & 0.196 \\
\hline $\begin{array}{l}\text { Tumor location } \\
\text { (Couinaud segment) } \\
\text { II/III/IV/VII/VIII }\end{array}$ & $\begin{array}{c}2(6.7) / 4(13.3) / \\
3(10.0) / 7(23.3) / \\
14(46.7)\end{array}$ & $\begin{array}{c}3(13.0) / 5(21.7) / \\
3(13.0) / 2(8.7) / \\
10(43.5)\end{array}$ & 0.597 \\
\hline
\end{tabular}

Values are presented as mean $\pm S D$, number (\%), or median (range).

RFA, radiofrequency ablation; HBV, hepatitis B virus; $H C V$, hepatitis C virus; AFP, a-fetoprotein; PIVKA-II, protein induced by vitamin $\mathrm{K}$ absence-II; ALBI, albuminbilirubin; INR, international normalized ratio.

Table 2. Ablation technique characteristics of the study patients

\begin{tabular}{lccc}
\hline \multicolumn{1}{c}{ Variable } & $\begin{array}{c}\text { Percutaneous RFA } \\
(\mathrm{n}=30)\end{array}$ & $\begin{array}{c}\text { Laparoscopic RFA } \\
(\mathrm{n}=23)\end{array}$ & P-value \\
\hline No. of electrodes & & & 0.061 \\
Single & $9(30.0)$ & $11(47.8)$ & \\
$\quad$ Clustered separable & $21(70.0)$ & $12(52.2)$ & \\
Overlapping ablation & & & 0.270 \\
No & $7(23.3)$ & $2(8.7)$ & \\
Yes & $23(76.7)$ & $21(91.3)$ & \\
\hline
\end{tabular}

Values are presented as number (\%).

RFA, radiofrequency ablation.

laparoscopic US, and RFA was conducted. Both technical success and efficacy were achieved in all 23 patients (100\%). 
Table 3. Ratio of the longest diameter and volume between ablation zone and tumor

\begin{tabular}{lccc}
\hline \multicolumn{1}{c}{ Variable } & $\begin{array}{c}\text { Percutaneous RFA } \\
(\mathrm{n}=30)\end{array}$ & $\begin{array}{c}\text { Laparoscopic RFA } \\
(\mathrm{n}=23)\end{array}$ & P-value \\
\hline $\begin{array}{l}\text { Ratio of longest diameter } \\
\text { (ablation zone/tumor) }\end{array}$ & $2.2(1.3-3.9)$ & $3.1(1.5-4.2)$ & $<0.001$ \\
$\begin{array}{l}\text { Ratio of volume } \\
\text { (ablation zone/tumor) }\end{array}$ & $9.1(2.4-30.2)$ & $19.7(3.4-58.2)$ & 0.002 \\
\hline
\end{tabular}

Values are presented as median (range).

RFA, radiofrequency ablation.

\section{Ablation Zone}

The median longest diameter of the ablation zone was $4.1 \mathrm{~cm}$ (range, 2.8 to $5.5 \mathrm{~cm}$ ) in the PRFA group and $4.7 \mathrm{~cm}$ (range, 3.3 to $6.0 \mathrm{~cm}$ ) in the LRFA group. The median volume of the ablation zone was $18.4 \mathrm{~cm}^{3}$ (range, 7.6 to $44.5 \mathrm{~cm}^{3}$ ) in the PRFA group and 28.7 $\mathrm{cm}^{3}$ (range, 8.4 to $43.5 \mathrm{~cm}^{3}$ ) in the LRFA group. The ratios of the longest diameter or the volume of the ablation zone to those of the tumors in both groups are summarized in Table 3 . The ablation zone was significantly larger in the LRFA group than the PRFA group in comparison to the tumor.

\section{Comparison of Therapeutic Outcomes \\ Cumulative LTP rate}

The median follow-up period was 51.9 months (range, 31.4 to 72.7 months) in the PRFA group and 57.1 months (range, 45.2 to 82.1 months) in the LRFA group. During follow-up, LTP was observed in 6 of 30 patients (20\%) in the PRFA group, whereas it did not occur in the LRFA group (Figs. 2, 3). The cumulative LTP rates at 1, 3, and 5 years were estimated to be $3.7 \%, 23.4 \%$, and $23.4 \%$, respectively, in the PRFA group and $0.0 \%$ in the LRFA group ( $\mathrm{P}=0.015$ ) (Fig. 4A).

\section{Cumulative IDR rate}

IDR was observed in 14 of 30 patients (46.7\%) in the PRFA group and nine of 23 patients (39.1\%) in the LRFA group during follow-up. The cumulative IDR rates at 1,3 , and 5 years were $14.1 \%, 45.1 \%$, and $50.6 \%$, respectively, in the PRFA group and $13.0 \%, 30.4 \%$, and $35.8 \%$, respectively, in the LRFA group ( $\mathrm{P}=0.304$ ) (Fig. 4B).

\section{Cumulative EM rate}

EM was observed in two of 30 patients (6.7\%) in the PRFA group during follow-up. Single pulmonary metastasis occurred 5 years after PRFA in one patient. Lobectomy was planned for metastasis, but the patient refused surgical treatment. In another patient, a single peritoneal seeding nodule occurred 2 years after PRFA, and surgical removal was done for the seeding nodule. IDR also developed in both patients. No EM was found in the LRFA group. The cumulative EM rates at 1, 3, and 5 years were estimated to be $0.0 \%, 4.0 \%$, and
$12.0 \%$, respectively, in the PRFA group and $0.0 \%$ in the LRFA group $(P=0.175)$ (Fig. 4C).

\section{DFS and OS}

As of April 30, 2021, seven of 30 patients (23.3\%) in the PRFA group and 1 of 23 patients (4.4\%) in the LRFA group died. The DFS rates at 1,3 , and 5 years were $82.2 \%, 38.6 \%$, and $32.2 \%$, respectively, in the PRFA group and $87.0 \%, 69.6 \%$, and $64.2 \%$, respectively, in the LRFA group ( $P=0.075$ ) (Fig. 4D). The OS rates at 1,3 , and 5 years were $96.6 \%, 85.7 \%$, and $71.6 \%$, respectively, in the PRFA group and $100 \%, 95.7 \%$, and $95.7 \%$, respectively, in the LRFA group ( $\mathrm{P}=0.049$ ) (Fig. 4E).

\section{Complications and Hospital Stay Duration}

Major complications were found in zero $(0 \%)$ patients in the PRFA group and one (4.4\%) patient in the LRFA group, respectively $(P=0.434)$. In one patient, lung and liver abscesses were found 8 months after LRFA. The patient was treated with antibiotics without external drainage.

The duration of the hospital stay was significantly different between the two groups (PRFA: median, 3 days; range, 3 to 3 days vs. LRFA: median, 5 days; range, 4 to 6 days; $P<0.001$ ).

\section{Discussion}

This study compared the treatment outcomes between LRFA and PRFA in patients with single, small $(1-3 \mathrm{~cm})$ subphrenic HCCs. Although LRFA required general anesthesia and a longer hospital stay than did PRFA (median, 5 vs. 3 days; $P<0.001$ ), both treatments were equally technically effective based on the 1-month followup CT images. The major complication rate was not significantly different between these two techniques. However, the LTP rate was significantly lower in the LRFA group than in the PRFA group. Notably, LTP was not observed in the LRFA group. The cumulative OS rate was significantly higher in the LRFA group than in the PRFA group. DFS rate was not significantly different between the two groups.

Studies directly comparing the outcomes between PRFA and LRFA for HCC are rare. LRFA has been reported to reduce the risk of multiple intrahepatic recurrences, including LTP, compared to PRFA [13]. However, more than half of a previous study population had tumors in other than subcapsular locations. In a large series [19], LTP was found in $15 \%$ of cases after LRFA, which appears to be higher than that in the present study. However, a direct comparison is difficult because the study population may be different, and only $35 \%$ of the tumors had superficial locations. As would be expected, the LTP rate was reported to be lower in subcapsular tumors $[19,20]$. 


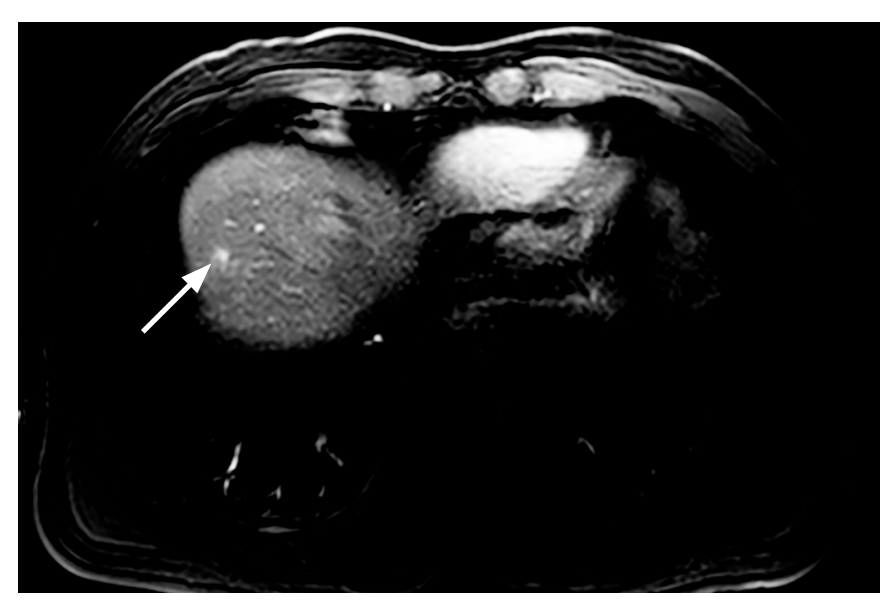

A

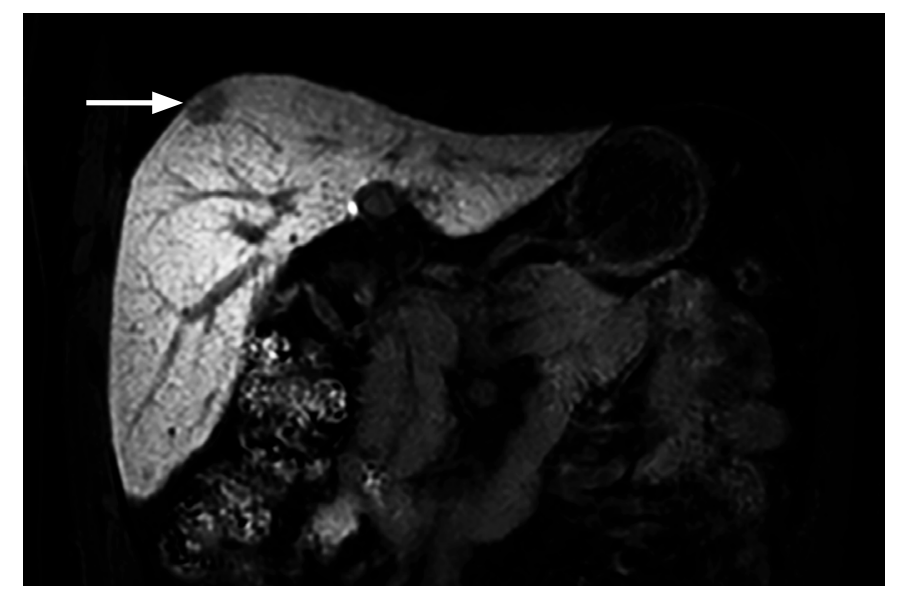

B

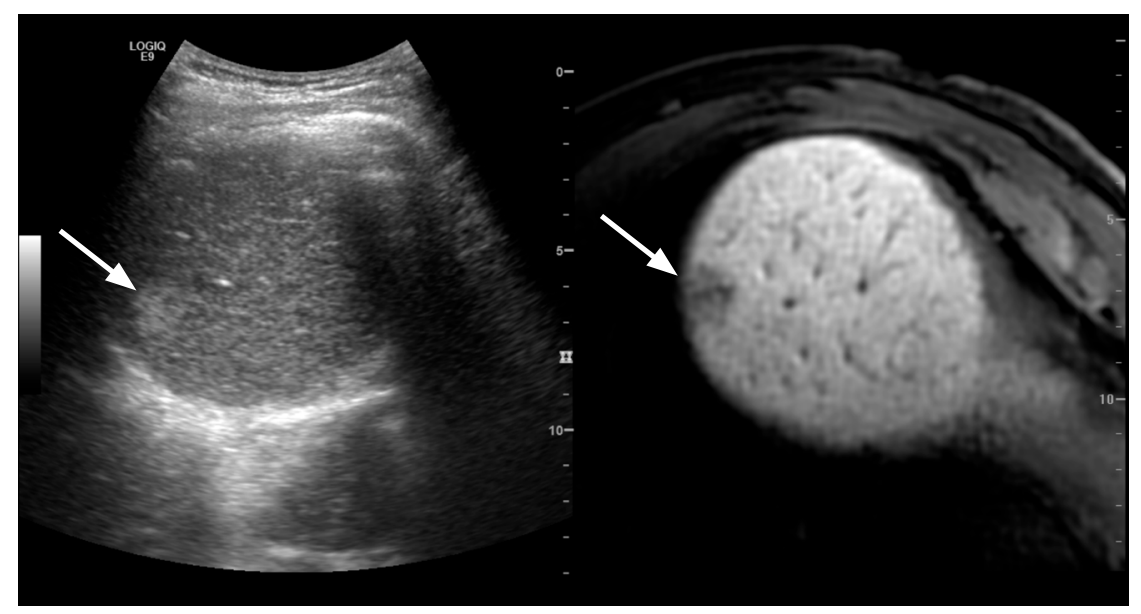

C

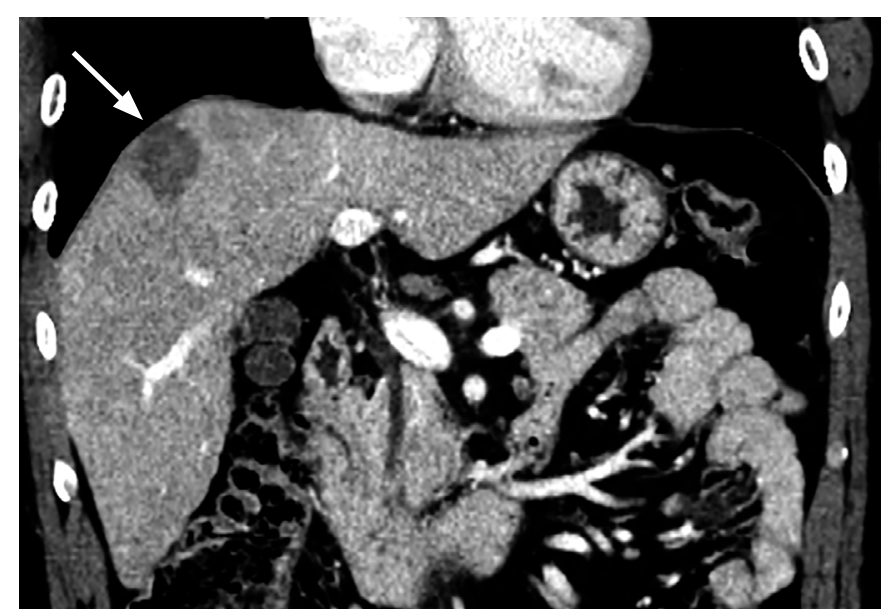

D

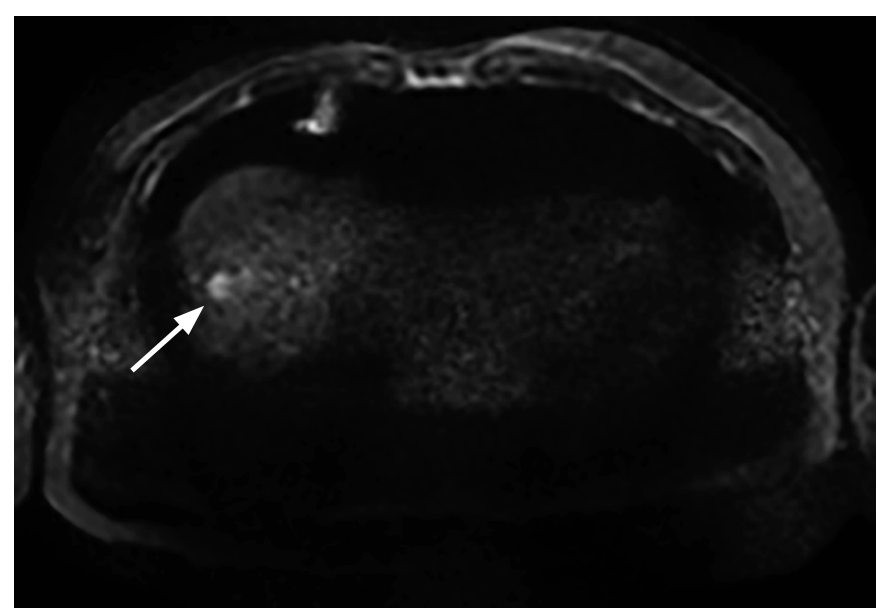

E

Fig. 2. Images of liver cirrhosis due to chronic hepatitis B viral infection in a 51-year-old man.

A. Axial arterial phase magnetic resonance image (MRI) shows a 1.9-cm hepatocellular carcinoma (arrow) in the subphrenic area of segment 8. B. Coronal hepatobiliary phase MRI shows a 1.9-cm hepatocellular carcinoma (arrow) in the subphrenic area of segment 8. C. Fusion imaging of real-time ultrasonography and MRI obtained before radiofrequency ablation (RFA) shows a slightly echogenic nodule (arrow) at the corresponding site (arrow) on the fused MRI in the right subphrenic area. D. Computed tomography image obtained immediately after percutaneous RFA shows complete ablation of the tumor (arrow). E. Diffusion-weighted MRI obtained 18 months after RFA shows a 1.1-cm local tumor progression (arrow) around the RFA zone. 


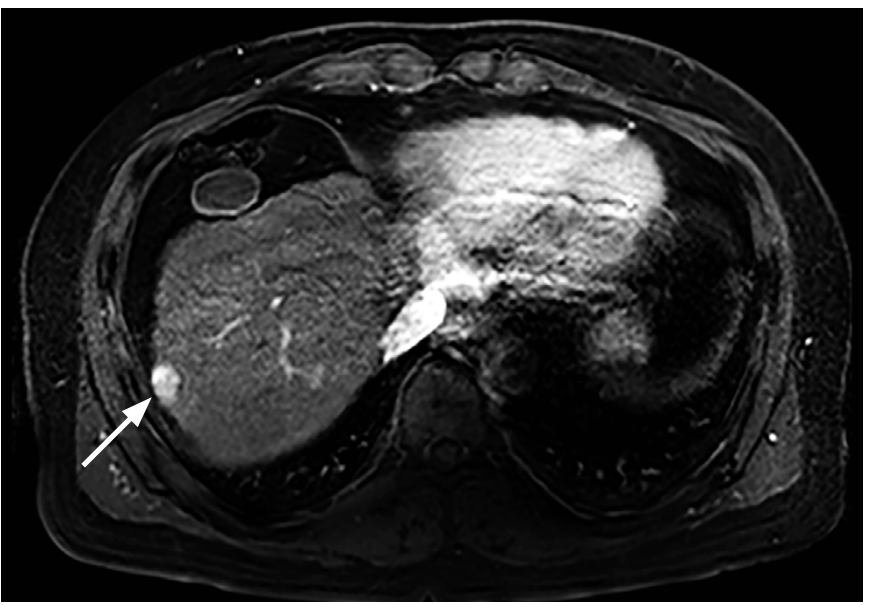

A

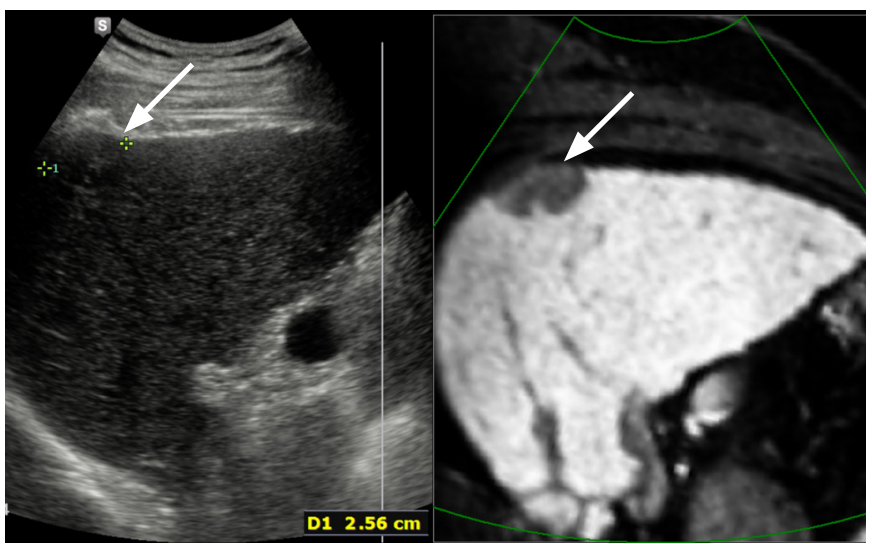

C

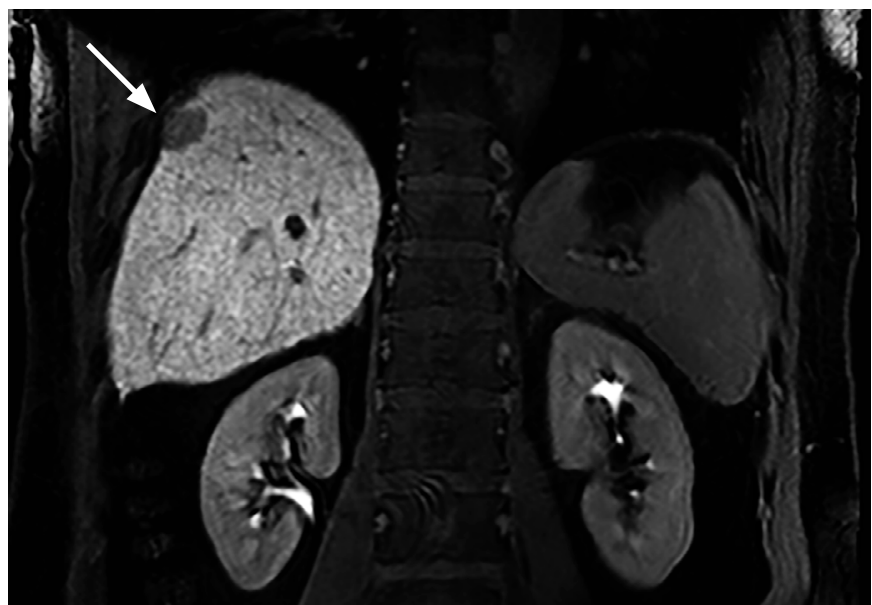

B

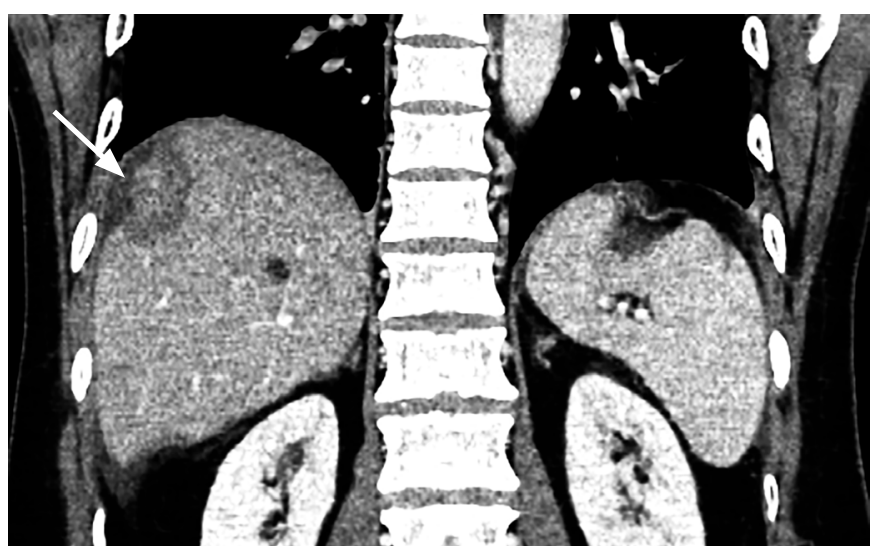

D

Fig. 3. Images of liver cirrhosis due to chronic hepatitis B viral infection in a 57-year-old man.

A. Axial arterial phase magnetic resonance image (MRI) shows a 2.6- $\mathrm{cm}$ hepatocellular carcinoma (arrow) in the subphrenic area of segment 8. B. Coronal hepatobiliary phase MRI shows a 2.6-cm hepatocellular carcinoma (arrow) in the right subphrenic area. C. Fusion imaging of realtime ultrasonography and pretreatment MRI shows a $2.6-\mathrm{cm}$ hepatocellular carcinoma (arrow) in the right subphrenic area. D. Computed tomography image obtained immediately after laparoscopic radiofrequency ablation shows that the tumor (arrow) is completely covered with a sufficient ablative margin. No local tumor progression was noted during the 71.4-month follow-up period.

A recent study found that invisible HCC on laparoscopy was a risk factor related to technical failure after initial LRFA attempts [14]. Therefore, subphrenic HCC visible on laparoscopy may be the best candidate for LRFA. Herein, the 5-year cumulative LTP rate significantly differed between the groups $(0.0 \%$ vs. $23.4 \%$, $\mathrm{P}=0.015)$. Since only subphrenic HCCs were included, excellent local tumor control after LRFA over PRFA may be expected.

Studies have examined the therapeutic outcomes after PRFA for subphrenic HCC. LTP was previously observed in $29 \%$ of subphrenic HCCs after PRFA, which was significantly higher than the $6 \%$ rate for non-subphrenic HCCs [11]. The cumulative LTP rates after PRFA were relatively high $(22.5 \%, 37.8 \%$, and $46.6 \%$ at 1,3 , and 5 years, respectively) [12]. These findings imply that subphrenic HCCs are challenging to control with PRFA under US guidance, even though artificial ascites is infused to enhance the sonographic window.

The difference in local tumor control between LRFA and PRFA may be attributed to the difference in technical difficulty. In PRFA, accurate electrode placement along the long trajectory under US guidance and obtaining a sufficient ablative margin along the liver surface are sometimes difficult for subphrenic tumors because the liver dome is difficult to visualize with US owing to the poor sonic window [3]. Furthermore, collateral thermal injury to the diaphragm may occur even with artificial ascites, which can lead to suboptimal ablation during PRFA. In LRFA, air is insufflated into the peritoneal cavity to provide sufficient space between the tumor and diaphragm. Therefore, it is possible to observe the liver dome directly and discriminate subphrenic tumors from the liver surface through the laparoscope. Thus, direct tumor puncture can be avoided by using 


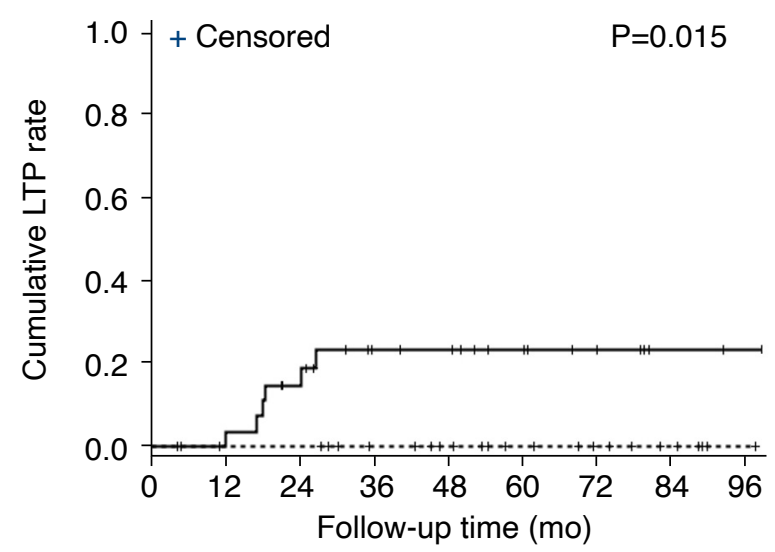

RFA - : Percutaneous RFA---: Laparoscopic RFA No. at risk

$\begin{array}{lllllllll}\begin{array}{l}\text { Percutaneous } 30 \\ \text { RFA }\end{array} & 27 & 21 & 14 & 13 & 9 & 5 & 2 & 1\end{array}$

$\begin{array}{lllllllll}\text { Laparoscopic } 23 & 23 & 23 & 19 & 15 & 11 & 8 & 5 & 1\end{array}$

A

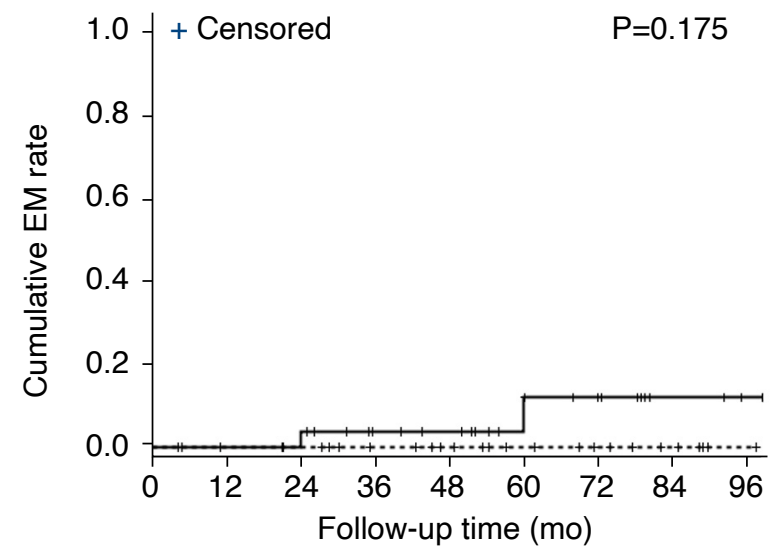

RFA — : Percutaneous RFA---: Laparoscopic RFA No. at risk

$\begin{array}{llllllllll}\text { Percutaneous } 30 & 27 & 25 & 19 & 17 & 12 & 8 & 3 & 1\end{array}$

$\begin{array}{lllllllll}\text { Laparoscopic } 23 & 23 & 23 & 19 & 15 & 11 & 8 & 5 & 1\end{array}$

C

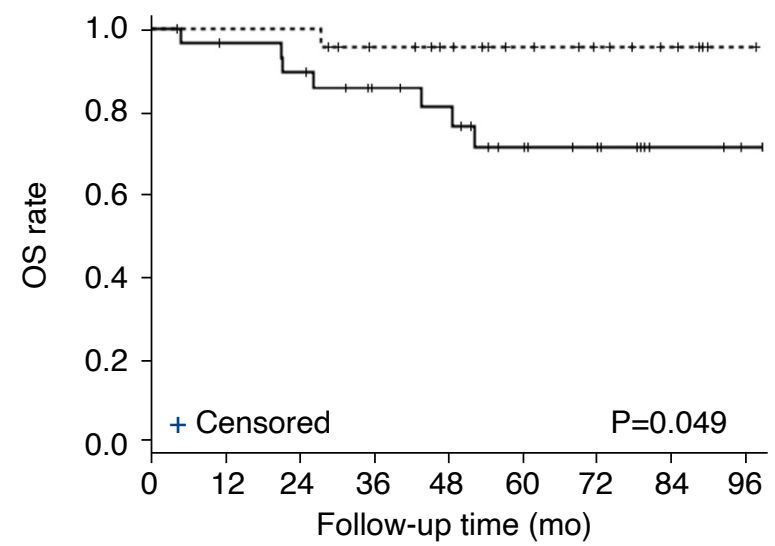

RFA — : Percutaneous RFA---: Laparoscopic RFA No. at risk

$\begin{array}{lllllllll}\text { Percutaneous } 30 & 27 & 25 & 20 & 18 & 12 & 8 & 3 & 1\end{array}$

$\begin{array}{llllllllll}\text { Laparoscopic } 23 & 23 & 23 & 19 & 15 & 11 & 8 & 5 & 1\end{array}$

E

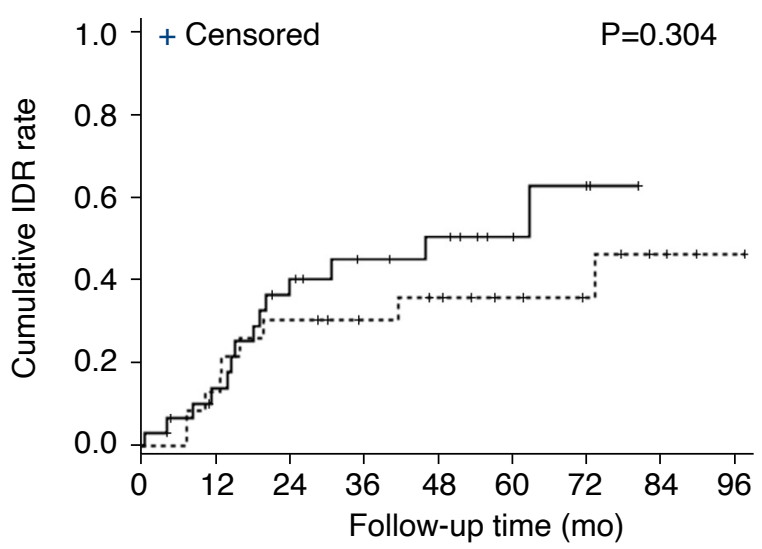

RFA — : Percutaneous RFA---: Laparoscopic RFA

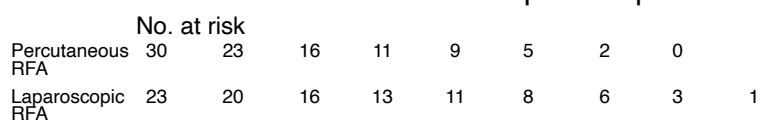

B

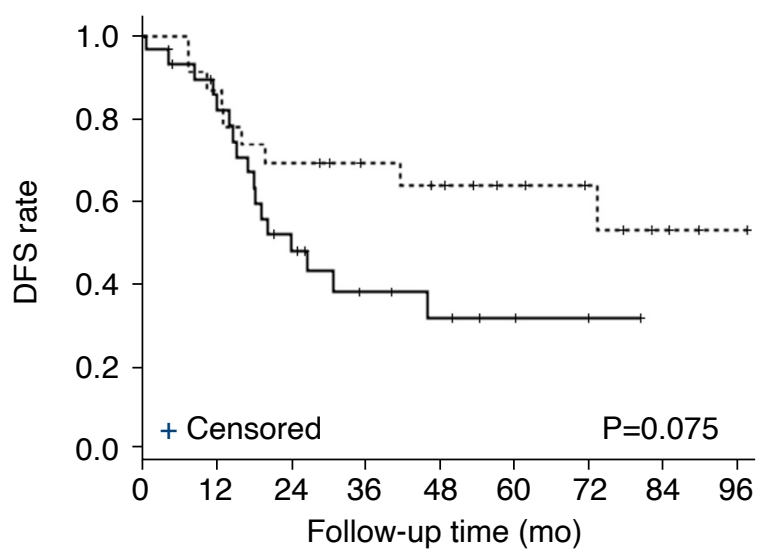

RFA - : Percutaneous RFA---: Laparoscopic RFA No. at risk

$\begin{array}{lllllllll}\text { Percutaneous } 30 & 23 & 13 & 7 & 5 & 3 & 1 & 0 & \\ \text { RFA } & 20 & 16 & 13 & 11 & 8 & 6 & 3 & 1 \\ \text { Laparoscopic 23 } & 20 & & & & & & \end{array}$

D

Fig. 4. Differences in the LTP, IDR, EM, DFS, and OS between PRFA and LRFA.

A. The cumulative LTP rate was significantly different between the PRFA and LRFA groups. B, C. The cumulative IDR rate (B) and the cumulative EM rate (C) was not significantly different between the PRFA and LRFA groups. D, E. The DFS rate was not significantly different (D) and the OS rate was significantly different (E) between the PRFA and LRFA groups. LTP, local tumor progression; IDR, intrahepatic distant recurrence; EM, extrahepatic metastasis; DFS, disease-free survival; OS, overall survival; PRFA, percutaneous radiofrequency ablation; LRFA, laparoscopic radiofrequency ablation; mo, months. 
multiple radiofrequency electrodes or multiple overlapping ablations. Consequently, sufficient ablative margins can be obtained after LRFA [14]. Moreover, patients' breathing can be controlled during general anesthesia, facilitating accurate needle placement.

In the present study, after LRFA, the ablation zone was significantly larger than that of the PRFA group in comparison to the tumor. This result may be explained by the following factors. First, in general, pneumoperitoneum associated with laparoscopic procedure results in up to a $40 \%$ reduction of portal venous flow, increasing the size of the ablation zone [21-24]. Second, direct tumor puncture was avoided based on visual inspection on laparoscopy, which would have resulted in a relatively peripheral tumor puncture or even no tumor puncture in the LRFA group, thereby enabling a larger ablation zone.

Tumor location is an important factor for LTP after RFA for HCC. Subphrenic tumor location was considered a risk factor for LTP after PRFA, but a factor associated with lower LTP rates after LRFA $[3,19,25]$. The results of the present study confirmed that local tumor control for subphrenic HCC is more effective with LRFA than with PRFA. Thus, LRFA can be applied for subphrenic HCC if the laparoscopic approach is technically feasible.

The DFS rate was higher in the LRFA group than in the PRFA group; however, the difference was not significant. The OS rate was significantly higher in the LRFA group than in the PRFA group. These results agree with previous findings that LRFA was significantly associated with favorable OS outcomes, while DFS was not significantly different between the groups [13].

The present study had several limitations. First, this was a retrospective, single-center study. Therefore, selection bias could not be avoided. Second, the sample size was relatively small because many patients were excluded as the present study focused on a specific tumor location. Therefore, exact matching between the groups was not feasible. However, there was no significant difference in patient and tumor characteristics between the two groups. Further well-designed prospective studies are warranted to verify the results. Third, the ablative margin-a factor related to local tumor control-was not assessed in the present study, as nearby anatomic landmarks such as hepatic vessels were usually far from the tumor due to the subphrenic tumor location, making it challenging to assess the ablative margin. Fourth, there may have been bias associated with each operator's preference, which may have influenced the choice between LRFA and PRFA.

In conclusion, LRFA showed better therapeutic outcomes in terms of LTP and OS than did PRFA for subphrenic HCC. Therefore, LRFA can be a valuable treatment option for subphrenic HCC if accessible using the laparoscopic approach.
ORCID: Min Hwan Kwak: https://orcid.org/0000-0003-0478-9507; Min Woo Lee: https://orcid.org/0000-0001-9048-9011; Seong Eun Ko: https://orcid.org/0000-00030007-6569; Hyunchul Rhim: https://orcid.org/0000-0002-9737-0248; Tae Wook Kang: https://orcid.org/0000-0002-0725-8317; Kyoung Doo Song: https://orcid.org/00000002-2767-3622; Jong Man Kim: https://orcid.org/0000-0002-1903-8354; Gyu-Seong Choi: https://orcid.org/0000-0003-2545-3105

\section{Author Contributions}

Conceptualization: Kwak MH, Lee MW. Data acquisition: Kwak MH, Lee MW, Ko SE, Rhim H, Kang TW, Song KD, Kim JM, Choi GS. Data analysis or interpretation: Kwak MH, Lee MW, Ko SE, Rhim H, Kang TW, Song KD. Drafting of the manuscript: Kwak MH, Lee MW. Critical revision of the manuscript: Kwak MH, Lee MW, Ko SE, Kang TW, Song KD, Kim JM, Choi GS. Approval of the final version of the manuscript: all authors.

\section{Conflict of Interest}

No potential conflict of interest relevant to this article was reported.

\section{Supplementary Material}

Video clip 1. Laparoscopic radiofrequency ablation procedure in a 63-year-old female with subcapsular hepatocellular carcinoma. The tumor was visible on laparoscopy as a pinkish mass with a bulging contour. Three electrodes were used and overlapping ablation was done for the posterior aspect of the tumor (https://doi.org/10.14366/ usg.21241.v001).

\section{References}

1. European Association for the Study of the Liver. EASL clinical practice guidelines: management of hepatocellular carcinoma. J Hepatol 2018;69:182-236.

2. Lai ZC, Liang JY, Chen LD, Wang Z, Ruan SM, Xie XY, et al. Do hepatocellular carcinomas located in subcapsular space or in proximity to vessels increase the rate of local tumor progression? A meta-analysis. Life Sci 2018;207:381-385.

3. Lee MW, Kang D, Lim HK, Cho J, Sinn DH, Kang TW, et al. Updated 10-year outcomes of percutaneous radiofrequency ablation as firstline therapy for single hepatocellular carcinoma $<3 \mathrm{~cm}$ : emphasis on association of local tumor progression and overall survival. Eur Radiol 2020;30:2391-2400.

4. Filippousis P, Sotiropoulou E, Manataki A, Konstantinopoulos O, Thanos L. Radiofrequency ablation of subcapsular hepatocellular carcinoma: single center experience. Eur J Radiol 2011;77:299-304.

5. Kim YJ, Raman SS, Yu NC, Busuttil RW, Tong M, Lu DS. Radiofrequency ablation of hepatocellular carcinoma: can subcapsular tumors be safely ablated? AJR Am J Roentgenol 2008;190:1029-1034. 
6. Poon RT, Ng KK, Lam CM, Ai V, Yuen J, Fan ST. Radiofrequency ablation for subcapsular hepatocellular carcinoma. Ann Surg Oncol 2004;11:281-289.

7. Kang TW, Lim HK, Lee MW, Kim YS, Rhim H, Lee WJ, et al. Longterm therapeutic outcomes of radiofrequency ablation for subcapsular versus nonsubcapsular hepatocellular carcinoma: a propensity score matched study. Radiology 2016;280:300-312.

8. Ishikawa T, Imai M, Ko M, Sato H, Nozawa Y, Sano T, et al. Effect of treatment support on preventing local recurrence of hepatocellular carcinoma directly adjacent to the diaphragm. Mol Clin Oncol 2017;7:61-66.

9. Rhim H, Lim HK. Radiofrequency ablation for hepatocellular carcinoma abutting the diaphragm: the value of artificial ascites. Abdom Imaging 2009;34:371-380.

10. Rhim H, Lim HK, Kim YS, Choi D. Percutaneous radiofrequency ablation with artificial ascites for hepatocellular carcinoma in the hepatic dome: initial experience. AJR Am J Roentgenol 2008;190:91-98.

11. Kang TW, Rhim H, Kim EY, Kim YS, Choi D, Lee WJ, et al. Percutaneous radiofrequency ablation for the hepatocellular carcinoma abutting the diaphragm: assessment of safety and therapeutic efficacy. Korean J Radiol 2009;10:34-42.

12. Song KD, Lim HK, Rhim H, Lee MW, Kang TW, Paik YH, et al. Hepatic resection vs percutaneous radiofrequency ablation of hepatocellular carcinoma abutting right diaphragm. World J Gastrointest Oncol 2019;11:227-237.

13. Eun HS, Lee BS, Kwon IS, Yun GY, Lee ES, Joo JS, et al. Advantages of laparoscopic radiofrequency ablation over percutaneous radiofrequency ablation in hepatocellular carcinoma. Dig Dis Sci 2017;62:2586-2600.

14. Ko SE, Lee MW, Min JH, Ahn SH, Rhim H, Kang TW, et al. Laparoscopic radiofrequency ablation of subcapsular hepatocellular carcinomas: risk factors related to a technical failure. Surg Endosc 2022;36:504-514.

15. Korean Liver Cancer Study Group (KLCSG); National Cancer Center, Korea (NCC). 2014 Korean Liver Cancer Study Group-National Cancer Center Korea practice guideline for the management of hepatocellular carcinoma. Korean J Radiol 2015;16:465-522.

16. Lee MW, Rhim H, Cha DI, Kim YJ, Lim HK. Planning US for percutaneous radiofrequency ablation of small hepatocellular carcinomas (1-3 cm): value of fusion imaging with conventional US and CT/MR images. J Vasc Interv Radiol 2013;24:958-965.

17. Ahmed M, Solbiati L, Brace CL, Breen DJ, Callstrom MR, Charboneau JW, et al. Image-guided tumor ablation: standardization of terminology and reporting criteria: a 10-year update. Radiology 2014;273:241-260.

18. Cha DI, Lee MW, Song KD, Ko SE, Rhim H. Ablative outcomes of various energy modes for no-touch and peripheral tumorpuncturing radiofrequency ablation: an ex vivo simulation study. Korean J Radiol 2022;23:189-201.

19. Santambrogio R, Barabino M, De Nicola E, Galfrascoli E, Giovenzana M, Zappa MA. Laparoscopic ablation therapies for hepatocellular carcinoma: could specific indications for the laparoscopic approach influence the effectiveness? Updates Surg 2020;72:435-443.

20. Della Corte A, Ratti F, Monfardini L, Marra P, Gusmini S, Salvioni $M$, et al. Comparison between percutaneous and laparoscopic microwave ablation of hepatocellular carcinoma. Int J Hyperthermia 2020;37:542-548.

21. Santambrogio R, Podda M, Zuin M, Bertolini E, Bruno S, Cornalba $G P$, et al. Safety and efficacy of laparoscopic radiofrequency ablation of hepatocellular carcinoma in patients with liver cirrhosis. Surg Endosc 2003;17:1826-1832.

22. Odeberg S, Ljungqvist 0 , Svenberg T, Gannedahl P, Backdahl M, von Rosen $A$, et al. Haemodynamic effects of pneumoperitoneum and the influence of posture during anaesthesia for laparoscopic surgery. Acta Anaesthesiol Scand 1994;38:276-283.

23. Jakimowicz J, Stultiens G, Smulders F. Laparoscopic insufflation of the abdomen reduces portal venous flow. Surg Endosc 1998; 12:129-132.

24. Cillo U, Vitale A, Dupuis D, Corso S, Neri D, D'Amico F, et al. Laparoscopic ablation of hepatocellular carcinoma in cirrhotic patients unsuitable for liver resection or percutaneous treatment: a cohort study. PLoS One 2013;8:e57249.

25. de la Serna S, Vilana R, Sanchez-Cabus S, Calatayud D, Ferrer J, Molina $V$, et al. Results of laparoscopic radiofrequency ablation for HCC. Could the location of the tumour influence a complete response to treatment? A single European centre experience. HPB (Oxford) 2015;17:387-393. 